\title{
REUSE OF NESTING SCRAPES BY KENTISH PLOVERS ${ }^{\perp}$
}

\author{
Juan A. Amat, Rosendo M. Fraga ${ }^{2}$ and Gonzalo M. Arroyo 3 \\ Estación Biológica de Doñana, C. S. I. C., Apartado 1056, E-41080 Sevilla, Spain, \\ e-mail: aguilar@cica.es
}

\begin{abstract}
We studied reuse of nesting scrapes within breeding seasons by Kentish Plovers (Charadrius alexandrinus) in an inland lake of southern Spain over six years. Overall, $5.6 \%$ of original nests were reused at least once. We tested whether nest reuse is adaptive, but found no differences in breeding success between those pairs that reused nests and those that did not. We also tested whether nest reuse should be more frequent when scrapes are difficult to excavate than when it is easier to excavate them, and found that nests on hard substrates were more frequently reused than nests on soft substrates, and that nest reuse was more frequent in the second half of the season, when the nesting substrate is harder, than in the first half of the season. This suggests that nest reuse may save Kentish Plovers some energy.
\end{abstract}

Key words: Charadrius alexandrinus, Kentish Plover, nesting sites, nesting success, reuse of nests.

Many bird species invest a considerable amount of time and energy in the construction of their nests. Some birds benefit from the investment made by others by usurping their nests. Cavity and enclosed nests are more frequently usurped than other types of nests, probably because cavity and enclosed nests are safer from predators (Lindell 1996). Other birds also may benefit from the investment made by others by using the nests of the original owners once the latter have finished breeding. This reuse of nests may occur either within or across breeding seasons. There are many species, such as secondary cavity nesters, that systematically breed in nests constructed by other species (Skutch 1976, Sedgwick 1997). In contrast, other bird species may construct their own nests, but also may reuse the nests of others to deposit their own clutches. Although there is some information on this facultative reuse of nests, it is mainly anecdotal, even though up to $20-50 \%$ of the clutches of some species are found in nests previously used by other individuals within

\footnotetext{
' Received 16 February 1998. Accepted 16 September 1998.

${ }^{2}$ Present address: Asociación Ornitológica del Plata, 25 de Mayo 749, 2-6, 1002 Buenos Aires, Argentina, e-mail: fraga@aorpla.org.ar

${ }^{3}$ Present address: Departamento de Biología Animal, Facultad de Ciencias del Mar, Universidad de Cádiz, Apartado 40, E-11510 Puerto Real, Spain, e-mail: gonzalo.munoz@uca.es
}

the same breeding season (Amat 1982, Rendón Martos and Johnson 1996).

Shorebirds nest on scrapes excavated on the ground. Tiny pebbles, debris, pieces of vegetation, and small mollusk shells may be added to these scrapes. This type of nest, especially if excavated on soft substrates such as sandy soils, is probably not very expensive to construct in comparison to more elaborate nests constructed by other species (Gauthier and Thomas 1993). Despite this, reuse of nests occurs among shorebirds (Skeel and Mallory 1996, Robinson et al. 1997). During a two-year study, Fraga and Amat (1996) reported a $6 \%$ reuse rate of nests in a Kentish Plover (Charadrius alexandrinus) population in southern Spain but did not analyze the characteristics of this nesting behavior. Here, we specifically focus on nest reuse by the same Kentish Plover population, using a more extensive data set.

Nest reuse in birds may be due to several causes. By reusing nests, birds may increase their breeding success because the body condition of adults that have not constructed their own nests may be better than those that did, or because they suffer lower nestling mortality than builders (Gauthier et al. 1994). Also, by reusing nests, some individuals may increase their mating opportunities in situations in which males use several nests during courtship (Ueda 1989). The reasons for these advantages are that birds may save a considerable investment of time and energy in reusing nests rather than in constructing new ones (Pearson 1974, Ueda 1989, Gauthier et al. 1994).

In this paper we test whether nest reuse within nesting seasons is adaptive. If it is, birds that reuse nests should have higher reproductive success than birds that do not. Moreover, Kentish Plover nests could be more frequently reused by conspecifics when it is difficult to get a site in which to excavate a scrape. Accordingly, we would expect that nests on stony substrates should be more often reused than those on alkali or sandy soils, and that nest reuse should be more frequent late in the season than earlier, because the soil becomes harder as the season advances due to lack of rains and warmer temperatures.

\section{METHODS}

Our study was conducted at Fuente de Piedra, a 13.5 $\mathrm{km}^{2}$ inland lake in Málaga province, southern Spain $\left(37^{\circ} 06^{\prime} \mathrm{N}, 4^{\circ} 45^{\prime} \mathrm{W}\right)$, during $1991-1996$. The lake is saline and shallow (water depth usually $<60 \mathrm{~cm}$ ). There are some dikes and islets in the lake that were constructed during the last century when the salt was commercially exploited (Rendón Martos and Johnson 
1996). Some of these dikes were covered with small stones. Kentish Plovers nest on the dikes, islets, and lakeshore (Fraga and Amat 1996). Except in 1996, the islets and dikes were accessible to terrestrial predators during part (1991) or even the whole breeding season (1992-1995), due to very low water levels.

Once a nest was found, it was individually marked, and we recorded its degree of cover, according to two categories: exposed, when the nest was covered < $25 \%$, and concealed, when the nest was covered $\geq$ $25 \%$, when viewed $1.5 \mathrm{~m}$ above it. These cover categories provided a reliable estimate of nest concealment, as recorded by measuring solar irradiance at the center of each nest (Fraga and Amat 1996). We also recorded whether or not the nest site had been previously used within the same nesting season, and whether it was in hard (stony) or soft (alkali or sandy) soil. The marks of nests were not removed until each breeding season had finished.

The masses of eggs in each nest were recorded with a portable Sartorius balance to the nearest $0.1 \mathrm{~g}$. If the laying date of a nest was not known, we estimated it by an equation that took into account the rate of daily mass loss of eggs during incubation (Fraga and Amat 1996). On average, laying dates were underestimated with this procedure by about two days. Laying dates could not be estimated for some nests, as they were found on very windy days when it was not possible to accurately record egg masses, and in the following visit the eggs had been preyed upon or had hatched. We considered early nests to be those initiated in the first half of the season, and late nests those initiated in the second half. Nests were revisited every 3-6 days to determine their fate. Nests were considered successful when at least one egg hatched. For unsuccessful nests, we assumed failure to have taken place midway between the last visit in which the nest was active and the following visit. Adults were captured using walkin traps and were individually marked with a metal band and a unique combination of color bands. Statistical tests were performed using SYSTAT (Wilkinson 1990).

\section{RESULTS}

In general, nests were reused only once $(5.1 \%$ of 826 original nests) within nesting seasons, although 3 nests were reused twice $(0.4 \%)$, and 1 nest was reused three times $(0.1 \%)$. Except in a few cases, the nests were reused by different pairs than those that originally constructed them. In one case in 1992, a nest was used four times, three of which by the same pair. In another case in 1996, a sequentially polygynous male had two nests at the same site. The percentages of nests that were reused each year were: $2.3(n=87)$ in 1991, 7.9 $(n=229)$ in $1992,7.4(n=136)$ in $1993,6.6(n=$ $152)$ in $1994,1.7(n=60)$ in 1995 , and $4.9(n=203)$ in 1996. There were no significant changes in the proportions of nests that were reused each year $\left(G_{5}=7.4\right.$, $P=0.19$ ),

There were no differences in breeding success between birds that reused nests $(16.0 \%$ of 50 pairs were successful) and those that did not $(26.2 \%$ of 822 pairs were successful) $\left(G_{1}=2.8, P=0.09\right)$. The breeding success of plovers that reused nests was not affected by the degree of nest concealment: 6 of 32 concealed nests were successful versus 2 of 18 exposed nests (Fisher exact test, $P=0.69$ ). The number of days elapsing between the date in which a nest became empty because of failure or success and reoccupation of the nesting site varied from 1-78. Although previously successful nests tended to be reoccupied sooner (17.0 \pm 15.5 days, $n=9$ ) than previously failed nests (25.0 \pm 19.5 days, $n=35$ ) after the original nest became empty, the difference was not significant (MannWhitney $U$-test, $U=185.5, P=0.42$ ).

Nests on stony substrates were as frequently reused (7.5\% of 241 ) as those on alkali or sandy soils combined $(5.2 \%$ of 636$)\left(G_{1}=1.6, P=0.21\right)$. Kentish Plovers reused nests less frequently in the first half of the season (1.9\% of 364 nests) than in the second half ( $8.9 \%$ of 474 nests) $\left(G_{1}=20.4, P<0.001\right)$.

For reused nests, there was an interaction between substrate type and degree of nest concealment: on soft substrates $77.4 \%$ of 31 reused nests were concealed versus $46.7 \%$ of 15 reused nests on hard substrates $\left(G_{1}\right.$ $=4.0, P<0.05$ ). The lower reuse of covered nests on hard substrates may indicate that the availability of covered nests to be reutilized may be more limiting in hard than in soft substrates, and that this low availability of covered nests may cause the plovers to make a greater reuse of exposed nests on such substrates. If this were really so, it could explain why frequencies of reutilization did not differ according to type of substrate (see above). When the effects of degree of cover are removed, there is indeed a relation between type of substrate and nest reuse (Mantel-Haenszel test, $\chi^{2}{ }_{1}$ $=3.9, P<0.05$ ), with nests on hard substrates being more frequently reused.

\section{DISCUSSION}

We were unable to find evidence that there was a fitness advantage to reusing nests. However, our results indicate that nest reuse was more frequent in situations where making nests would presumably be more difficult, and this may save Kentish Plovers some energy. In spite of this, the frequency of nest reuse by shorebirds is low (Skeel and Mallory 1996, Robinson et al. 1997 ), probably because scrapes are not very costly to excavate.

We thank Dirección General de Investigación Científica y Técnica (DGICYT, grants PB92-0115 and PB95-0110) and Junta de Andalucía (Plan Andaluz de Investigación, research group RNM 0105) for financial support of this study. During field work, R. M. Fraga held a fellowship from Ministerio de Educación y Ciencia (DGICYT program "Estancias Temporales de Científicos Extranjeros en España"). The Consejería de Medio Ambiente, Junta de Andalucía, authorized our work at the Reserva Natural Laguna de Fuente de Piedra, and provided housing facilities. The director of the Nature Reserve, M. Rendón, provided us with facilities. Our appreciation also to A. Arroyo, R. Camarena, J. M. Ramírez, J. Rubio, M. Siquier, and M. Vázquez for field assistance. F. Alvarez, W. D. Koenig, and two anonymous referees commented on previous drafts of the manuscript. 


\section{LITERATURE CITED}

AмAт, J. A. 1982. The nesting biology of ducks in the Marismas of the Guadalquivir, south-western Spain. Wildfowl 33:94-104.

Fraga, R. M., AND J. A. AMAT. 1996. Breeding biology of a Kentish Plover (Charadrius alexandrinus) population in an inland saline lake. Ardeola 43:69-85.

Gauthier, M., and D. W. Thomas. 1993. Nest site selection and cost of nest building by Cliff Swallows (Hirundo pyrrhonota). Can. J. Zool. 71: 1120-1123.

Gauthier, M., D. W. Thomas, J. R. Speakman, and H. LAPIERRE. 1994. Bénéfices associés à la réutilisation des nids chez l'Hirondelle à Front Blanc (Hirundo pyrrhonota). Écoscience 1:119-126.

LiNDELL, C. 1996. Patterns of nest usurpation: when should species converge on nest niches? Condor 98:464-473.

PEARSON, D. L. 1974. Use of abandoned cacique nests by nesting Troupials (Icterus icterus): precursor to parasitism? Wilson Bull. 86:290-291.

Rendón Martos, M., AND A. R. Johnson. 1996. Man- agement of nesting sites for Greater Flamingos. Colonial Waterbirds 19(Spec. Publ. 1):167-183.

Robinson, J. A., L. W. Oring, J. P. Skorupa, AND R. BOETTCHER. 1997. American Avocet (Recurvirostra americana). In A. Poole and F. Gill [eds.], The birds of North America, No. 275. The Academy of Natural Sciences, Philadelphia, and The American Ornithologists' Union, Washington, DC.

SEdGwick, J. A. 1997. Sequential cavity use in a cottonwood bottomland. Condor 99:880-887.

SkeEl, M. A., AND E. P. MalloRy. 1996. Whimbrel (Numenius phaeopus). In A. Poole and F. Gill [eds.], The birds of North America, No. 219. The Academy of Natural Sciences, Philadelphia, and The American Ornithologists' Union, Washington, DC.

Skutch, A. F. 1976. Parent birds and their young. Univ. Texas Press, Austin, TX.

UEDA, K. 1989. Re-use of courtship nests for quick remating in the polygynous Fan-tailed Warbler Cisticola juncidis. Ibis 131:257-262.

WILKINSON, L. 1990. SYSTAT: the system for statistics. SYSTAT, Inc., Evanston, IL.

\title{
OUTWARD MIGRATION OF HOUBARA BUSTARDS FROM TWO BREEDING AREAS IN KAZAKHSTAN ${ }^{1}$
}

\author{
Olivier Combreau, Frederic Launay and Mohammed Al Bowardi \\ N.A.R.C., P.O. Box 45553 Abu Dhabi, U.A.E., \\ e-mail:narc@emirates.net.ae \\ BORIS GUBIN \\ Institute of Zoology NAS RK, Akademgorodok, Almaty 480032, Kazakhstan
}

\begin{abstract}
We studied the migration patterns of nine Houbara Bustards (Chlamydotis undulata macqueenii) from two breeding areas in the Republic of Kazakhstan by tracking via satellite during two consecutive seasons. All the birds from the Taukum desert (east Kazakhstan) migrated southwest towards the Kyzylkum desert and then south-southeast towards Iran, south Afghanistan, and north Baluchistan. All the birds from the Buzachi peninsula (west Kazakhstan) migrated south towards Turkmenistan and Iran and then west towards south Iraq. Houbara followed similar migration routes in 1995 and 1996. All birds bypassed natural obstacles such as seas and mountains. The total distance covered by Houbara during their outward migration ranged from 1,600 to $2,320 \mathrm{~km}$. We observed important interindividual variation in migration timing, duration, and patterns. Migration duration ranged from
\end{abstract}

\footnotetext{
${ }^{1}$ Received 9 February 1998. Accepted 13 July 1998.
}

14-73 days. Travel rate between the breeding grounds and the wintering grounds was 24 to $151 \mathrm{~km} \mathrm{day}^{-1}$, with up to $323 \mathrm{~km}$ covered in one day.

Key words: central Asia, Chlamydotis undulata macqueenii, Houbara Bustard, migration, satellite tracking.

The Houbara Bustard (Chlamydotis undulata) inhabits desert, semi-desert, and arid shrublands, and ranges from the Canary Islands across North Africa to the Middle East and Central Asia (Cramp and Simmons 1980, Johnsgard 1991, Collar 1996). The Asian subspecies (C. u. macqueenii) is distributed from the Middle East to Mongolia and is the main quarry for Arab falconers. The Asian Houbara is a regular winter visitor in the Arabian Peninsula, the wintering birds arriving in eastern Arabia in September-October and starting their return migration in February-March (Sheldon and Launay 1998). 